\title{
INVESTIGATION OF THE NON-THERMAL PLASMA-BASED ADVANCED OXIDATION PROCESS FOR REMOVAL OF ORGANIC CONTAMINANTS IN AZO DYES SOLUTION
}

\section{Tota Pirdo Kasih ${ }^{1}$}

1 Department of Industrial Engineering, Bina Nusantara University, Jl. KH. Syahdan, No. 9, Palmerah, 11480 Jakarta, Indonesia, e-mail: tkasih@binus.edu

Received: 2016.12.27

Accepted: 2017.01.24

Published: 2017.03.01

\begin{abstract}
The present study deals with the development of non-thermal plasma-based AOPs for removal of organic contaminants in wastewater treatment. The plasma itself is generated based on point-to-point geometry under organic solution and can generate hydroxyl radicals, ozone, peroxide and other radicals as the basic species to destruct organic contaminants. Electrical diagnostic in a form of voltage and current waveform was investigated through the variation of time during the formation of plasma channeling. The evolutions of plasma channeling with its physical phenomena were also discussed. The relationship between the electrodes distance towards applied voltage to sustain the plasma were also studied. It was found that the mineralization occurred during plasma treatment to transform the harmful functional group in organic dye solution into harmless species. Simultaneously, the decoloration process by using this submerged plasma treatment system is able to change the orange color of methyl orange solution into clearly transparent water in 30 minutes. The present findings may provide the plasma-based advanced oxidation process as a promising chemical-free and cost competitive AOP process application on specially the waste water treatment in textile industry.
\end{abstract}

Keywords: plasma-AOPs, organic waste treatment, submerged plasma channels, dye decoloration

\section{INTRODUCTION}

Textile effluents are generally known of having a great potential to the serious environmental problems. This is because the polluted effluents from this industry have the undesirable color, odor, harmful chemicals and other possibly hazardous organic contaminants which are very dangerous for the survival of aquatic life if the waste water is discharged directly into the lakes or rivers. Many kinds of organic colorants are used in textile industry; however, the complex composition and more stable types of azo dyes are dominating by making up to $60 \%$ of the utilized colorants in textile industry and have been proved as major contaminants in the effluents [Jiang et al.
2012, Dojčinović et al. 2012]. Conventional biological wastewater treatment seems to be less effective because the organic azo contaminants are more difficult to degrade and it takes more time for complete processing. The similar case is for the chemical treatment, which is costly due to the requirement a large amount of chemicals and requires further treatment for the by-product sludge.

Advanced oxidation processes (AOPs) obtained great considerable attention from many researchers to become a solution method for the lacks of treatment [Al-Kdasi et al 2004]. The principle processing AOPs is the removal of organic contaminants from waste water through oxidation reaction with hydroxyl radicals. It is generally known that hydroxyl radical is the highest non- 
toxic radicals; having oxidation potential of $2.8 \mathrm{~V}$ [Xin et al. 2015] and can more efficiently oxidize almost all organic compounds in water [Shimizu et al. 2013]. Recently, most of AOPs methods are based on UV/peroxide and UV/ozone as an advanced waste water treatment [Kartohardjono et al. 2012]. Another AOP method receiving increased interest from researchers is non-thermal plasma, which can be applied either above the water surface or underwater. Interaction of the nonthermal plasma with the water will yield many reactive species, such as $\mathrm{OH}^{*}, \mathrm{O}^{*}, \mathrm{H}^{*}, \mathrm{HO}_{2}{ }^{*}$, $\mathrm{O}_{3}, \mathrm{H}_{2} \mathrm{O}_{2}$ and simultaneously, emitting UV, visible light and generate shockwaves [Ruma et al. 2015, Gunnar et al. 2015]. A specific advantage of plasma-based AOP is the in-situ generation of hydroxyl radicals and another reactive species without the addition of costly chemicals and UV lamps [Pekárek 2003, Gerrity et al. 2010].

The present study deals with the investigation of the non-thermal plasma-based advanced oxidation process for removal of organic contaminants in azo dyes solution. Methyl orange was selected as a model of azo dye solution and the plasma channel was generated in the solution with consideration that all electrical energy transfer will be absorbed for solution heating with a little energy loss and thus accelerate the formation of more chemical species and physical phenomena which will lead to the highly efficient interaction between the plasma and solution during the removal process of organic contaminants.

\section{EXPERIMENTAL}

Figure 1 shows the schematic diagram of the experimental set up for the purification process of water containing organic azo dye. Two electrodes of $2 \mathrm{~mm}$ in diameter of stainless steel were immersed in $150 \mathrm{ml}$ methyl orange (MO) solution inside of the glass chamber and separated with the distance of $2 \mathrm{~mm}$ in between. This style of electrode arrangement is usually called by point-topoint geometry. The parts of electrodes immersed in solution were enveloped by isolator except at the edge of the pins. One electrode connected to the HV source, the other one is grounded. The several amounts of voltages were applied to understand its relationship with the distance of the pins. On the other part, the plasma treatment time was conducted to investigate its correlation with the solution temperature. The temperature of the MO solution was monitored by using IR thermometer. The concentration of the MO solution is made by diluting $9 \mathrm{ml} \mathrm{MO}$ indicator into 450 $\mathrm{ml}$ mineral water. The conductivity of mineral water was $329 \mu \mathrm{S} / \mathrm{cm}$, measured by Mettler Toledo S47-K SevenMulti conductivity meter. AC high voltage as the electric source that can supply up to $10 \mathrm{KV}$ was used to generate the plasma inside the water solution. Electrical measurement was performed by using a high probe PD-28 with the attenuation ratio of 1000:1 and a current probe. The signals from those two probes were monitored using a digital oscilloscope (Hantek DSO5072P). Investigation of molecular structure

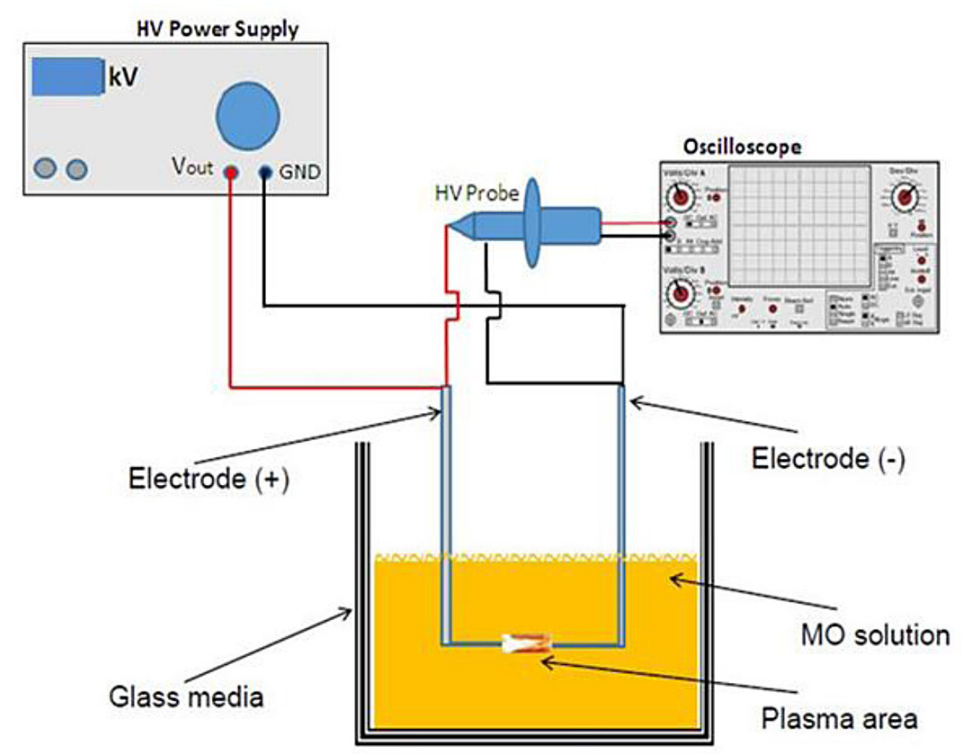

Figure 1. Schematic diagram of non-thermal plasma-based AOP system for removal of organic contaminants in organic azo dye solution 
of methyl orange dye was done after drying the solution and was carried out by means of FTIR, Thermo-Fisher Scientific, iN-10.

\section{RESULTS AND DISCUSSIONS}

\section{Electrical diagnostic}

Figure 2 shows the voltage and the current waveforms of plasma discharge underwater as variations of time. The amplitude of current is about 2.4 A p-p, whereas the applied voltage to sustain the plasma was $660 \mathrm{~V} \mathrm{p}$-p, acquired at the frequency of $50 \mathrm{~Hz}$. The existence of spikes both in voltage and current waveforms confirm the conductive plasma channel between two submerged electrodes have been formed and sustained.

\section{Evolution of plasma channeling in submerged solution}

The discharge plasma under MO solution was observed by using digital microscope and the visualized pictures were presented on Figure 3. Step by step processes of the configuration of plasma channeling can be explained by the following as the fundamental characteristics of discharge underwater. The first step was the formation of bubbles surrounding the electrode tips when a small amount of voltage was applied. The bubbles were changed into rapid formation of micro-bubbles and the movement becomes faster by increasing the applied voltage. This process confirms the intensive heating through the flowing of current between the two pins initiates solution evaporation. No light emission or any sound was observed at this stage which occurred below $500 \mathrm{~V}$.

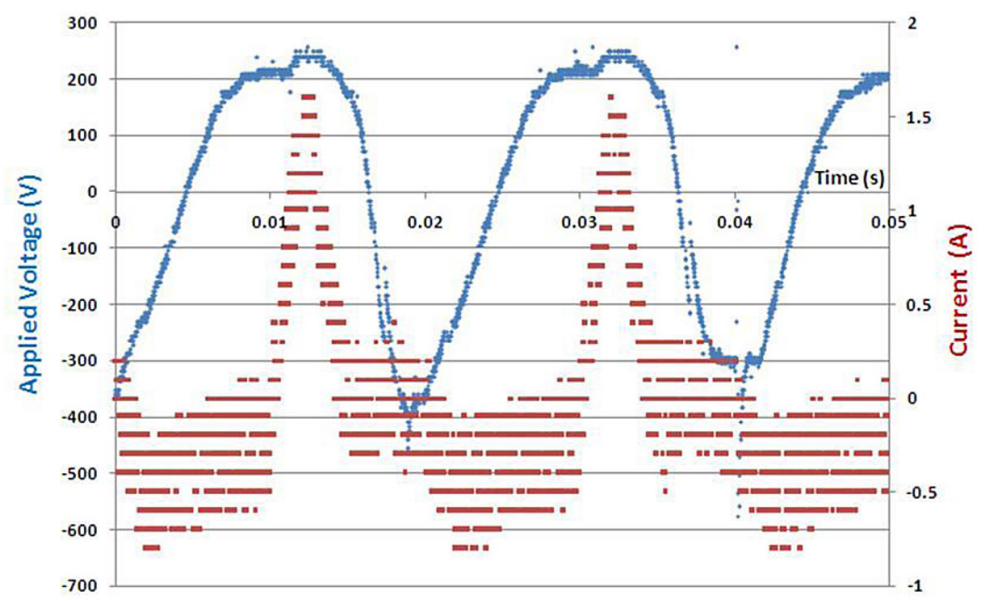

Figure 2. Typical waveform of voltage and current during discharge underwater with $2 \mathrm{~mm}$ in distance of point-to-point electrodes geometry
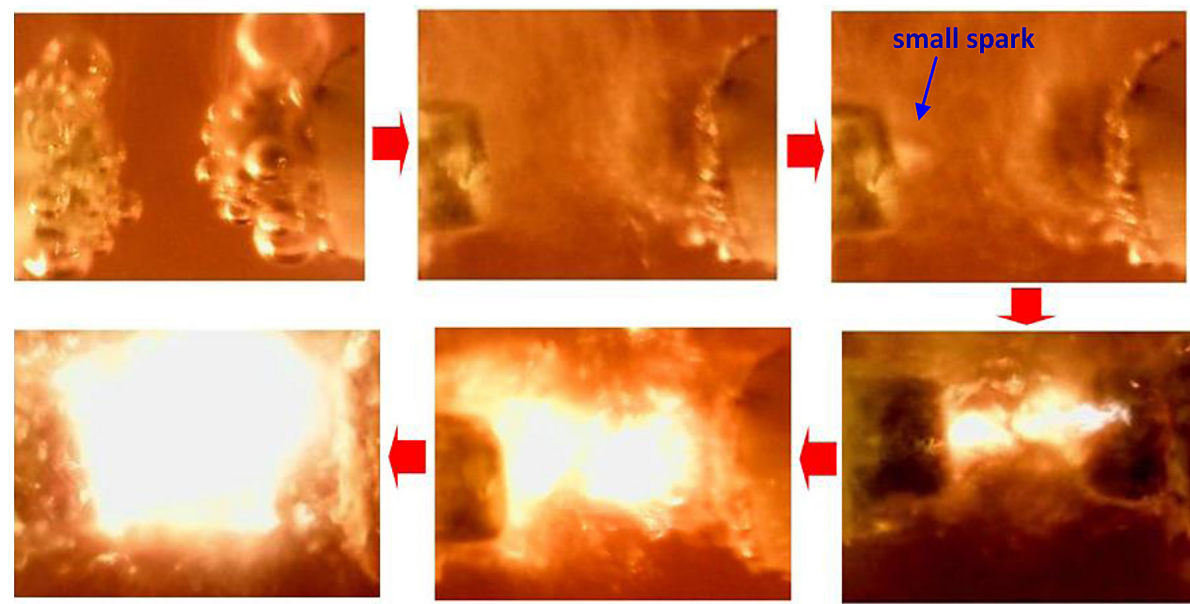

Figure 3. The formation of plasma channeling under methyl orange solution with $2 \mathrm{~mm}$ in distance of point-to-point electrode geometry 
Enhancement applied voltage to $550 \mathrm{~V}$ brought to the formation of small spark discharge at the grounded pins to start the ionization process of water vapor, whereas the other pins continuing heating the solution through the formation of micro bubbles. At this stage, electrical breakdown was reached and the physical phenomenon-during this period can be detected in a form of slight noise and little shockwave. More energy deposited through further increase of voltage gave rise to the formation of plasma channeling in between the submerged electrodes. The electric channeling becomes bigger and stronger by increasing the voltage, followed by intense noise and rigorous shockwaves. The conductive channeling turned into arcing when the voltage reached $1000 \mathrm{~V}$.

\section{Effect of electrode distance on applied voltage}

Figure 4 presents the relationship between the electrode distance and applied voltage to generate plasma in the solution. It should be noted that the measurements of applied voltage in this case were based on the generation of sustainable plasma channeling and not the formation of initial breakdown/sparks. An almost linear relationship between those two variables can be seen from the graphics. Energy deposited into the solution to form the plasma channeling was compensated through the increasing of applied voltage when the electrodes distance value become bigger.

\section{FTIR Analysis}

FTIR analysis was performed to distinguish the molecular structure of methyl orange solution before and after plasma treatment. Figure 5 displays the FTIR spectra of dried methyl orange solution before and after plasma treatment. The spectrum of dried MO exhibits some important of functional groups of $-\mathrm{C}=\mathrm{C}$ - in aromatic rings at region $1606(1)$, aromatic $-\mathrm{CH}$ stretching at $2923(2),-\mathrm{N}=\mathrm{N}-$ azo function at 1422 (3), $-\mathrm{S}=\mathrm{O}$ at 1123 (4), $-\mathrm{CH}$ bonds in methyl group (5) and $-\mathrm{CH}$ bonds in 'para' benzene at 818 and 847 [Nandini et al. 2012, Tingting et al. 2015]. Plasma treatment of MO solution was done under the applied voltage of $660 \mathrm{~V}$ for various treatment times. Electrical energy plasma seems very high causing not only degradation or deformation of MO molecules but also proceed the destruction process to eliminate almost all of the functional groups, including hazardous azo group, as can be seen at FTIR spectrum under $1800 \mathrm{~cm}^{-1}$

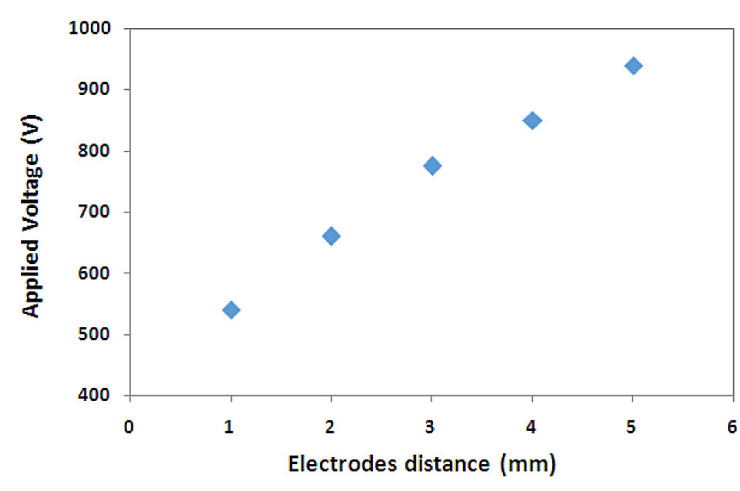

Figure 4. The effect of various electrodes distance in MO solution on the applied voltage needed to sustain plasma channeling

for 10 minutes plasma treatment. Those original MO groups were possibly transformed into the more safe molecules through the reaction with hydroxyl radicals, other reactive oxidants, UV light and shockwaves which were generated during submerged plasma treatment. This also confirms the process of mineralization of $\mathrm{MO}$ organic compounds into harmless groups. FTIR of $20 \mathrm{mnt}$ plasma treatment shows unremarkable difference spectrum with the $10 \mathrm{mnt}$ treatment. Decoloration process was also proceeded simulteneously during submerged plasma treatment. Figure 6 shows the color degradation of $\mathrm{MO}$ solution in various plasma treatment times under applied voltage of $660 \mathrm{~V}$. By observing the changing color of orange into clearly transparent, it can be said that in this condition the methyl orange solution was completely decolorized in $30 \mathrm{mnt}$ of plasma treatment.

\section{CONCLUSION}

Non-thermal plasma-based AOPs have been investigated for removal organic contaminants in methyl orange dye solution. By using pointto-point geometry with electrodes distance of 2 $\mathrm{mm}$, the applied voltage of $660 \mathrm{~V}$ can sustain the plasma channels through delivering a current of $2.4 \mathrm{~A}$ into the solution. The developed plasma confirms the destruction of organic compounds in methyl orange (MO) including the dangerous azo groups and verify the transformation of those organic contents into the harmless species through mineralization process. In this condition, $150 \mathrm{ml}$ methyl orange solution could be completely decolorized into clearly transparent harmless water in 30 minutes. This research opens the high prospective of non-thermal plasma as a competitive AOP system into the potential application in textile industries for wastewater treatment. 
a)

b)
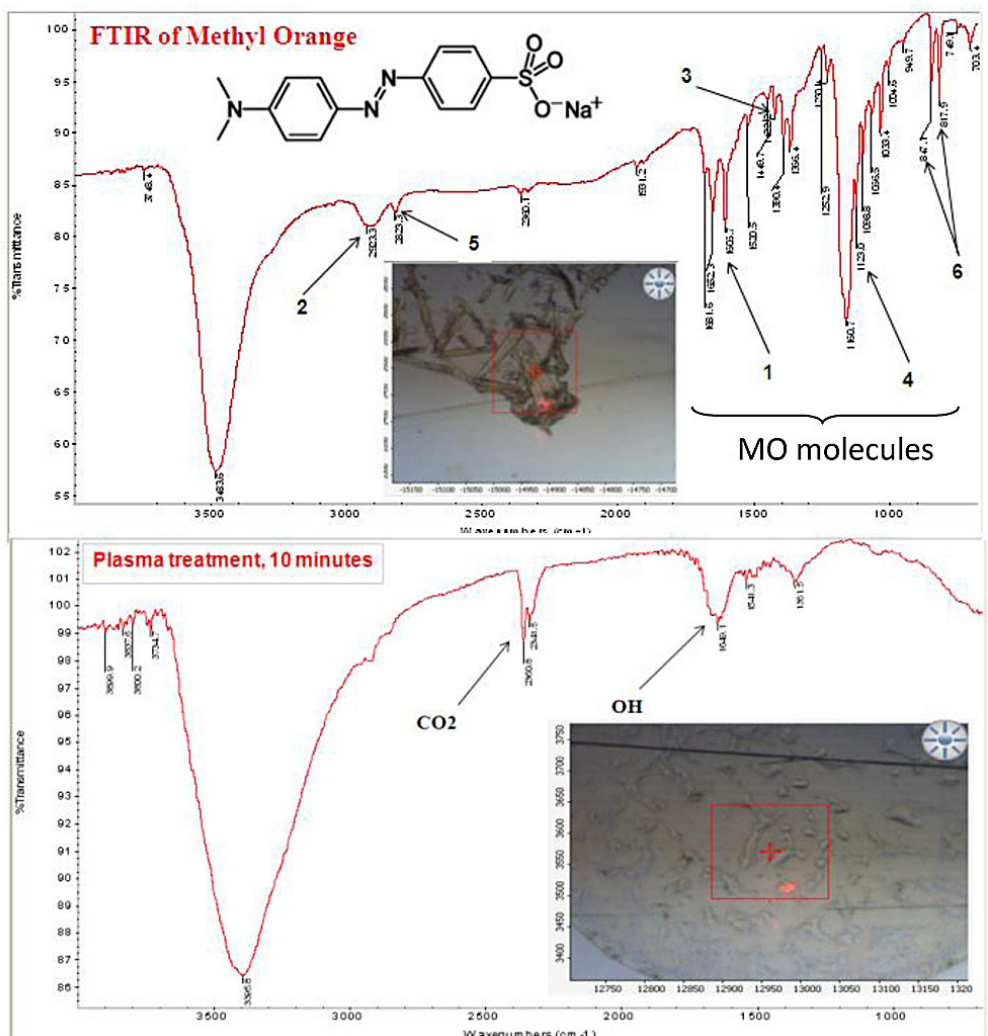

c)

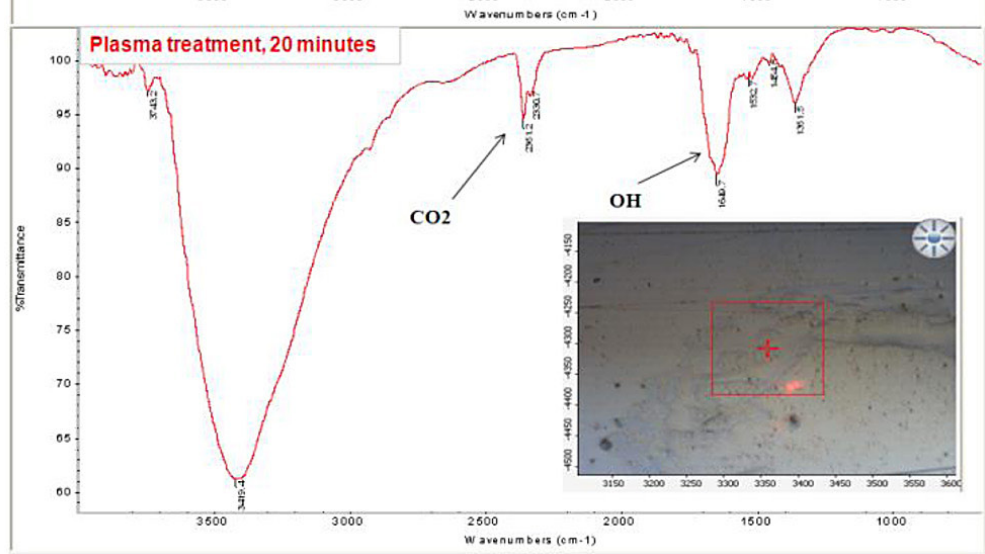

Figure 5. FTIR spectra of (a) dried methyl orange and dried MO after (b) $10 \mathrm{mnt}$, (c) $20 \mathrm{mnt}$ plasma treatment

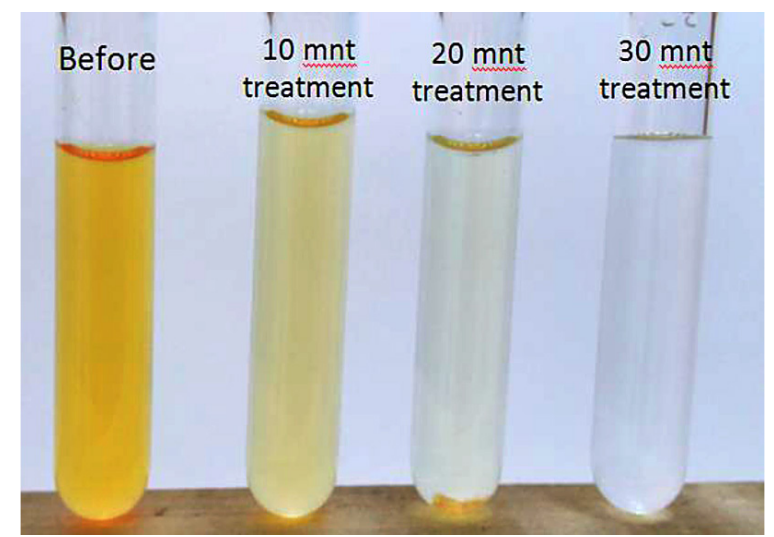

Figure 6. Photograph of degradation of color of $\mathrm{MO}$ solution under $660 \mathrm{~V}$ plasma treatment at different period of times 


\section{Acknowledgments}

This work was supported by a Grant from the Kurita Water and Environment Foundation Research Grant (KARG) Program.

\section{REFERENCES}

1. Al-Kdasi A., Idris A., Saed K. and Guan C-T. 2004. Treatment of textile wastewater by advance oxidation processes. Global NEST Journal, 6(3), $222-230$.

2. Dojčinović B.P., Roglić G.M., Obradović B.M., Kuraica M.M., Tosti T.B., Marković M.D. and Manojlović DD. 2012. Decolorization of Reactive Black 5 using a dielectric barrier discharge in the presence of inorganic salts. Journal of the Serbian Chemical Society, 77(4), 535-548.

3. Gerrity D., Stanford B.D., Trenholm R.A. and Snyder S.A. 2010. An evaluation of a pilot-scale nonthermal plasma advanced oxidation process for trace organic compund degradation. Water Research, 44 (2), 1597-1610.

4. Gunnar R.S, Christopher L.B., Fei Dai, Thomas M.H. and Selma M.T. 2015. Plasma-based water treatment: Conception and application of a new general principle for reactor design. Chemical Engineering Journal, 273, 543-550.

5. Jiang B., Zheng J., Liu Q. and Wu M. 2012. Degradation of azo dye using non-thermal plasma advanced oxidation process in a circulatory airtight reactor system. Chemical Engineering Journal, 204-206, 32-39.

6. Kartohardjono S., Handayani P.L., Deflin S., Nuraeni Y. and Bismo S. 2012. Ammonia removal from wastewater through combination of absorption process in the membrane contactor and advance oxydation process in hybride plasma-ozone reactor. Journal of Environmental Science and Engineering A1, 1101-1107.

7. Nandini R. and Vishalakshi B. 2012. A study of interaction of methyl orange with some polycations. E-Journal of Chemistry, 9 (1), 1-14.

8. Pekárek S. 2003. Non-thermal plasma ozone generation. Acta Polytechnica, 43 (6), 47-51.

9. Ruma, Habib M.A., Hosseini S.H.R., Sakugawa T. and Akiyama H. 2015. Treatment of wastewater by underwater discharge in gas bubbling water. International Journal of Renewable Energy and Environmental Engineering, 3(3), 189-194.

10. Shimizu K., Masamura N. and Blajan M. 2013. Water purification by using microplasma treatment. Journal of Physics: Conference Series 441, 1-7.

11. Tingting S., Chengcheng J., Chen W., Jing S., Xikui W. and Xiaoming L. 2015. A $\mathrm{TiO}_{2}$ modified abiotic-biotic process for the degradation of the azo dye methyl orange. RSC Advances, 5, 58704-58712.

12. Xin L., Huimin Z, Dandan Q., Yang Y., Ying K., Fang Z. and Zucheng W. 2015. Radical-initiated decoloration of methylene blue in a gas-liquid multiphase system via DC corona plasma. Plasma Chemistry and Plasma Processing, 35, 321-327. 